\begin{tabular}{lcl}
\hline Bentham open & The Open Materials Science Journal \\
CrossMark & Content list available at: www.benthamopen.com/TOMSJ/ \\
\hline
\end{tabular}

RESEARCH ARTICLE

\title{
Constitutive Modelling for Anisotropic Damage in Woven E-Glass Reinforcements
}

\author{
Ping Yang ${ }^{*}$ and Ying Tong \\ College of Mechanical and Electrical Engineering, Chongqing College of Electronic Engineering, Chongqing 401331, \\ China
}

\begin{abstract}
It is easy for composite laminates to be damaged by relative lower velocity impact which could give rise to internal delamination that will strongly weaken the compressive strength of laminates. In order to predict the occurrence of matrix failure, the elastic-brittle behaviors of fiber-reinforced composites were modeled constitutively by an anisotropic damage model. The dynamic tensile testing was performed at a constant velocity of $2 \mathrm{~mm} / \mathrm{min}$ until the sample broke to achieve the mechanical parameters of Eglass reinforcements. The elastic constitutive equation and the constitutive damage model were obtained on basis of the fundamental theory of mechanics about the orthotropic constitutive of reinforcements. The methodology for this constitutive model which is developed by Hashin considered both the effect of fiber and matrix failure. Then, the developed constitutive equations were incorporated into the FE (finite element) codes, ABAQUS, through the user subroutine module to simulate the process of projectile impacting GFRP composite laminates. The results show that the material deformation reaches a maximum at $24 \mu$ s, then occurs rebound with the increase of the time. The stress of reinforcements traverse section linearly increases outward from 0 MPa to 509.8 $\mathrm{MPa}$. Material damage area increases with the prolonging of time, and for a fixed time, material damage gradually increases from the edges to the center and reaches a constant value of 1 , which means the rupture of the damage process.
\end{abstract}

Keywords: Fiber-reinforced Composites, Numerical simulation, Constitutive model, Damage, E-Glass Reinforcements.

\section{INTRODUCTION}

Fiber-reinforced composites have been widely used in some structural components in aircrafts on account of their multiple advantages such as lower thermal expansion and weight, higher specific stiffness, corrosion resistance and strength [1, 2]. It is well known that the properties of fiber-reinforced composites vary from matrix-dominant to fiberdominant behavior [1], since they show strong anisotropic mechanical behavior according to their fiber orientations. Fiber-reinforced laminated composites are susceptible to transverse impact, especially transverse impact at low velocities which gives rise to significant damage inside composites in terms of matrix cracks and delamination, meanwhile inner damage is difficult to be detected with eyesight. The inner damage induces the obvious decrease in the stiffness and strength, and cumulative damage contributes most to the failure process of fibrous composite materials with non-ductile matrices. As a result, the damage of composite structure caused by the relative lower velocity impact inhibits their widespread applications in manufacturing [3]. In recent years, numerous investigations involving fiberreinforced composites have been conducted on this subject, which contributes to the prediction of composite stiffness failure mechanisms, failure modeling, impact performance and non-orthogonal constitutive equation [4 - 16].

The relative lower velocity impact damage in laminates has been considered as a main threat for a long time [17]. A lot of efforts have been paid to analyzing the impact behaviors of laminate structures, but few efforts have been devoted to the damage analysis of velocity impact on composites so far. Hou et al. [18] constructed a 3D FE model including three criteria based on failure stresses in order to analyze the whole process of damage onset and propagation in velocity

\footnotetext{
* Address correspondence to this author at the College of Mechanical and Electrical Engineering, Chongqing College of Electronic Engineering, Chongqing 401331, China; Tel: 15922900904; E-mails: yangping2_2015@126.com, tongying2004@126.com
} 
impacted laminates. Zheng et al. [19] proposed a double Mindlin type plate model involving a improved virtual crack closure method to analyze the lower velocity impact. Johnson et al. [2] proposed a model on the basis of continuum damage mechanics to analyze the inter-laminar and intra-laminar failures during the loading process of velocity impact.

The GFRP laminates consist of epoxy resins and glass-fiber, thus the main fracture mechanisms for GFRP laminates includes two aspects, fiber failure and matrix failure. However, few attention has been paid to the integrated effects of fiber failure and matrix failure in constitutive damage modelling for GFRP laminates. The methodology for this constitutive model was developed by Hashin (1980) in which fiber mode and matrix mode, two distinct fatigue failure modes, were considered and modelled. In Hashin's mathematical model, five coefficients closely related to strength parameters can be obtained and dirived from simple uniaxial tensions and compressions. In the following sections, firstly, the uniaxial tensile tests were performed at a constant velocity of $2 \mathrm{~mm} / \mathrm{min}$ until the samples broke to achieve the mechanical parameters of E-glass reinforcements. Secondly, the basic mechanics theory about the orthotropic constitutive modelling of reinforcements is used to construct the Hashin constitutive damage model and analyze the impact behavior of composite structures. Finally, the developed constitutive equation was incorporated into a finite element code by using finite element method (FEM) on ABAQUS software, and the simulation procedure of bullet impacting GFRP laminates was realized in this way.

\section{EXPERIMENTAL PROGRAMS}

\subsection{Material}

The glass fiber reinforced composite (GFRP) studied is composed of polyacrylonitrile derived glass fibers in a resin matrix. A plain weave was used as a basic single-layer element design for one-layer fabric because due to its excellent performance. GFRP having fiber packing possesses a higher density which results in a higher strength, meanwhile GFRP possesses long floats and thus a lower crimp. The diameter of an E-glass fiber is approximately $9 \mu \mathrm{m}$, and it has less than $1 \%$ alkali chemically. The E-glass fiber has tensile strength $3448 \mathrm{MPa}$, elastic modulus $72.4 \mathrm{GPa}$, elongation 4.8\%. The E-glass plain weaves were prepared by interlacing warp thread and fill thread as shown in Fig. (1). The Eglass plain weave woven with reinforcement adopted has a specific mass of $600 \mathrm{~g} / \mathrm{m}^{2}$ with approximately 6 warp ends per $\mathrm{cm}, 4.5$ weft picks per $\mathrm{cm}$, in another word it has a density of $2.54 \mathrm{~g} / \mathrm{cm}^{3}$. The matrix resin has Polyester mixed up with catalyst hardener ensuring a density of $1.21 \mathrm{~g} / \mathrm{cm}^{3}$. The basic structural element is a laminated plate containing cross-woven E-glass cloth consisting of continuous glass filaments. Panel of thirteen element layers of E-glass woven fabrics was laminated to a thickness of $8 \mathrm{~mm}$ under the pressure of $100 \mathrm{MPa}$ on a vulcanizing machine for forty-eight hours. Fig. (2) shows the homogeneity of the structure obtained by mixture of E-glass cloth with the resin. In the material, the overall fiber volume fraction is approximately $40 \%$, and the resin volume fraction is approximately $60 \%$.

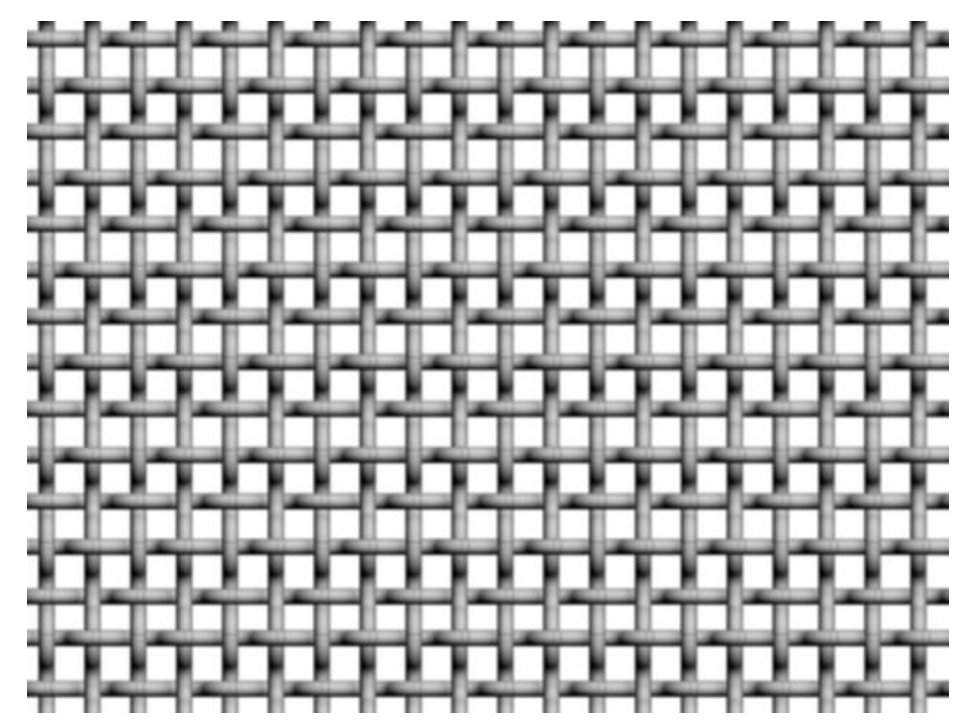

Fig. (1). Schematic drawing of plain weave E-glass fabric. 


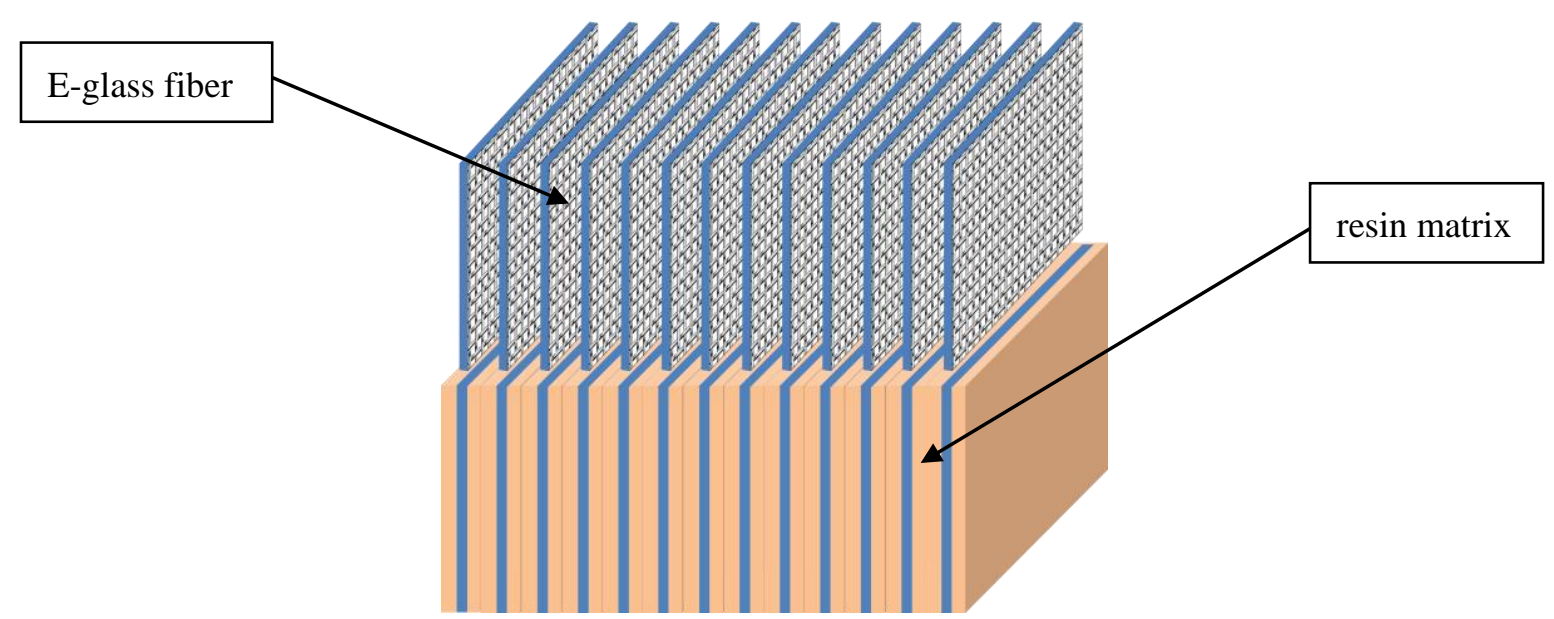

Fig. (2). Structure of the laminated composite material tested.

\subsection{Sample Preparation for Tensile Tests}

Specimen is important for a tensile test as it determines the measuring results of stress-strain relationships. The specimen must conform to exact physical dimensions and must be no wrinkles, precision cutting and free of burrs and nicks. Here a precision milling machine and hand finishing were adopted, then the required configurations were achieved. Laminated composite samples with thirteen element layers of E-glass woven fabrics were prepared in panel form for cutting into the appropriate pattern, or pattern plating of the appropriate form. Epoxy resin was used as the material matrix. Laminated composite samples were prepared through a hand lay-up process. The lay-up chosen of the laminate was $\left[0^{\circ} / 90^{\circ}\right] \mathrm{S}$ which provided a fully symmetric arrangement. A $\left[0^{\circ} / 90^{\circ}\right]$ lay-up for the glass plies ensured that uncured epoxy resin and hardener were respectively infiltrated into the $0^{\circ}$ and $90^{\circ}$ plies.

The tensile samples may be in the form of "dog-bone" samples as described in Chinese Standard GB/T1446-2005, Type-1, and their plane geometry and dimensions are illustrated as Fig. (3a). Fig. (3b) shows the specimen dimensions for testing Poisson's ratio with aluminum sheets adhered to its two ends as described in Chinese Standard GB/T1447-2005. The aluminum sheet strengthens the ends of composite specimen, and ensures the first crack to appear in the middle of specimen.

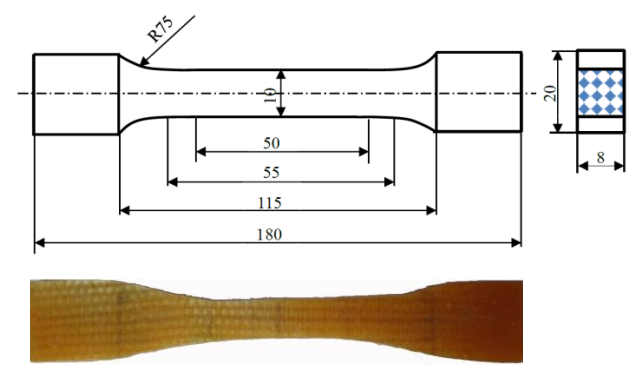

(a)
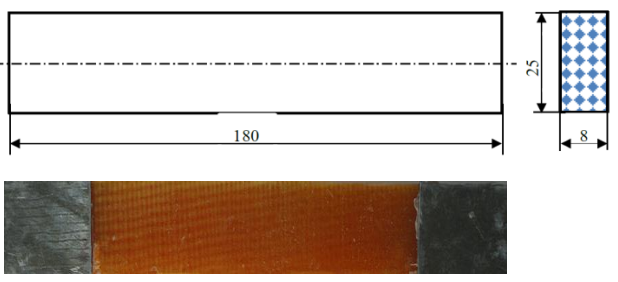

(b)

Fig. (3). Geometry and dimensions of (a) tensile specimen; (b) rectangular poison's ratio specimen. 


\subsection{Test Procedure}

The setup of the dynamic tensile testing is presented in Fig. (4). Tensile testing aims to evaluate the ability of a material to sustain pulling forces and the stretching extent before breaking. In a tensile testing process, one end of the sample is clamped while another one is pulled at a constant velocity of $2 \mathrm{~mm} / \mathrm{min}$ until the sample is broken. Strain represents the length change resulted from pulling per unit of beginning length. The output of such a tensile test is a load versus elongation curve as shown in Fig. (5a) which will be converted into a curve about engineering stress versus engineering strain as shown in Fig. (5b). The engineering stress and the engineering strain data can be obtained by dividing the load and elongation by some constant values such as geometry informations). Fig. (5b) represents a typical engineering stress versus engineering strain curve, from which it can be seen that stress increases continuously along with strain and linearly up to a sudden drop (i.e. fracture).

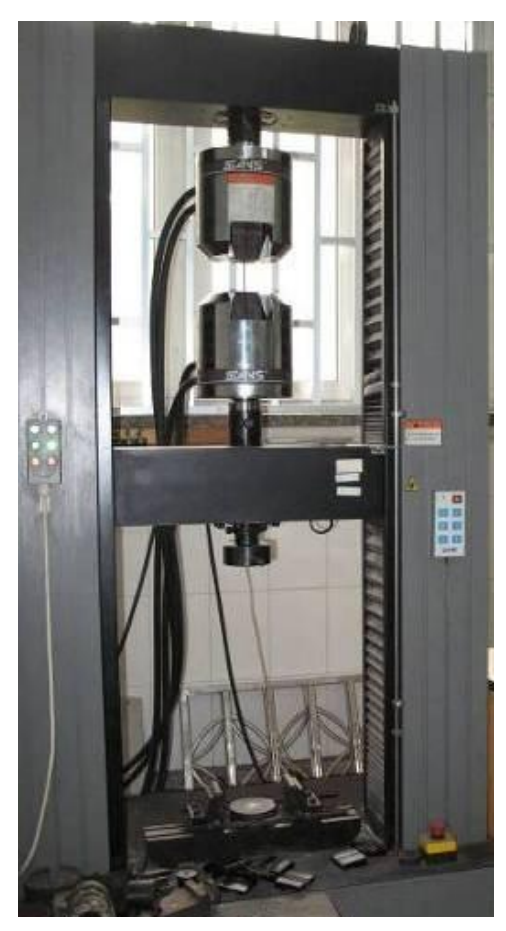

Fig. (4). Test set-up for high speed tensile testing.

In addition, during a tensile test for Poisson's ratio, the elastic lateral strains need to be measured accurately, while their values of laminated composite samples reinforced with E-glass woven fabrics in a tensile test are usually very small. Therefore, in order to perform the reasonably accurate measurement of Poisson's ratio, a very sensitive extensometer (strain gages) is always used for lateral strains. Fig. (6) represents the lateral strain versus longitudinal strain curve which indicates a linear relationship.

\section{RESULTS AND DISCUSSION}

\subsection{Linear Elastic Characteristics in Microstructures}

Fig. (5b) shows that the engineering stress increases linearly and then exits when the engineering strain passes the maximum value, 0.018. Meanwhile, from Fig. (6), it can be seen that the lateral compressive strain increases linearly along with the longitudinal strain increasing up to 0.018 . The linear elasticity is valid due to the fact that stress states do not produce yielding. In Fig. (7a) the observation by optical microscope reveal that the fracture of the laminated composite reinforced with E-glass woven fabrics is smooth, which indicates that the material has negligible ductility. Fig. (7b) shows that the E-glass woven fabrics in the laminated composite have been pulled out from their matrix, and the curved E-glass fibers have become straight under large pullout energy. The observations reveal that the laminated composite reinforced with E-glass woven fabrics is also a kind of linear elastic material. 


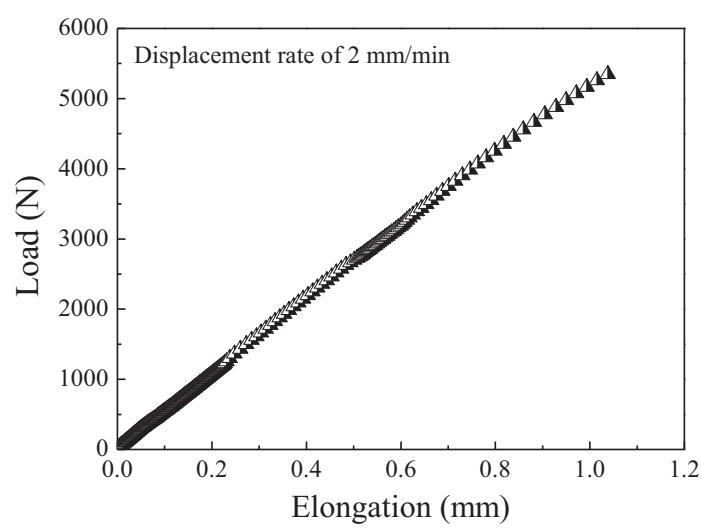

(a)

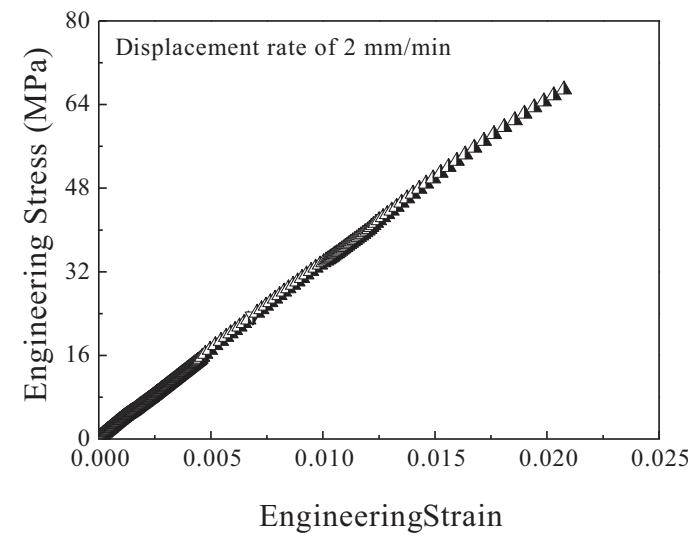

(b)

Fig. (5). Tensile property in principal direction: (a) load versus elongation curve; (b) engineering stress versus engineering strain curve.

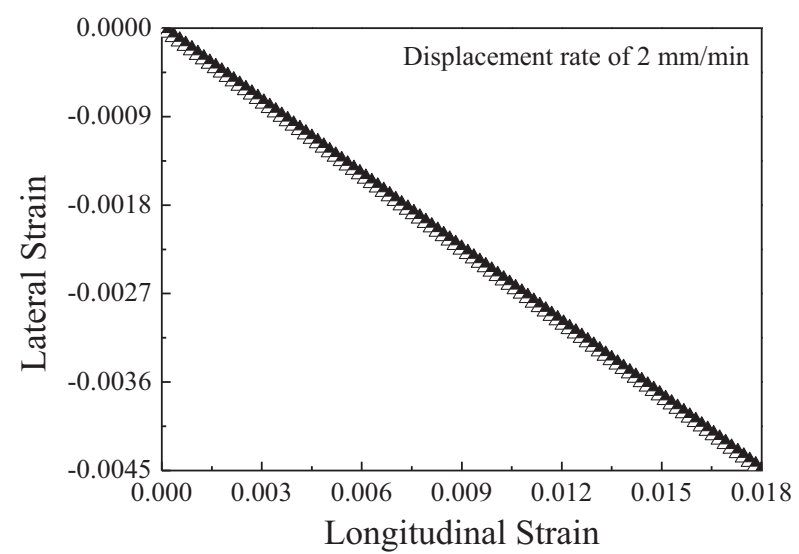

Fig. (6). Lateral strain versus longitudinal strain curve. 


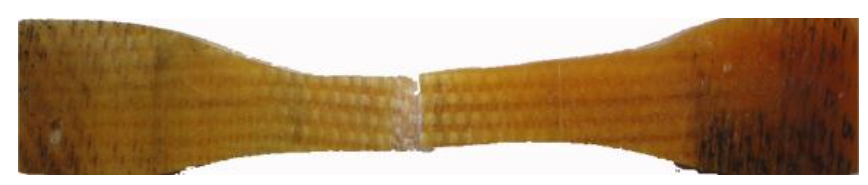

(a)

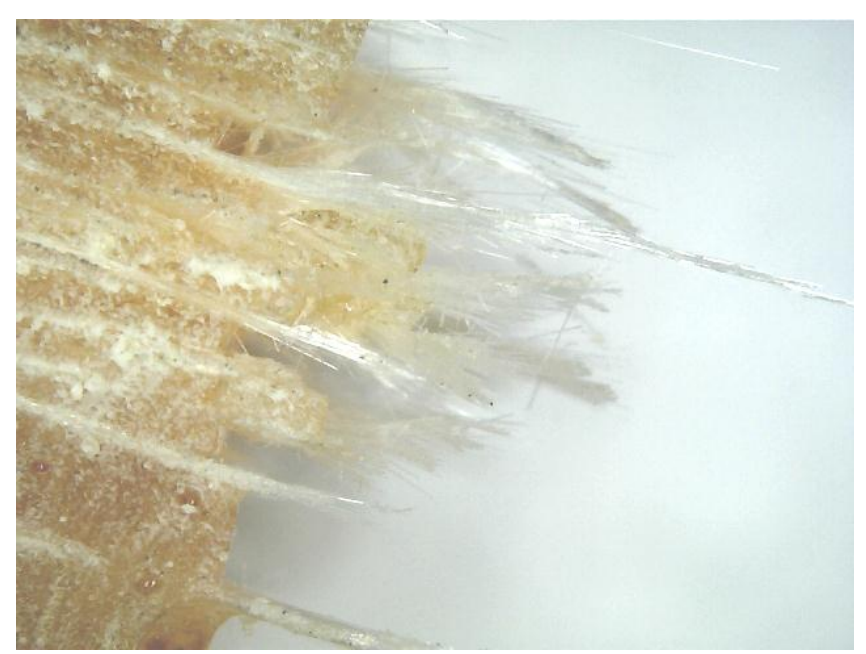

(b)

Fig. (7). Failure of specimen (a) fracture; (b) failure fiber.

\subsection{Elastic Constitutive Model}

In the coordinate system of 2D woven reinforced composite layer plate shown in Fig. (8), $x_{1}$ and $x_{2}$ indicate the direction of laying fiber longitudinal and transverse directions while $x_{3}$ represents the thickness direction.

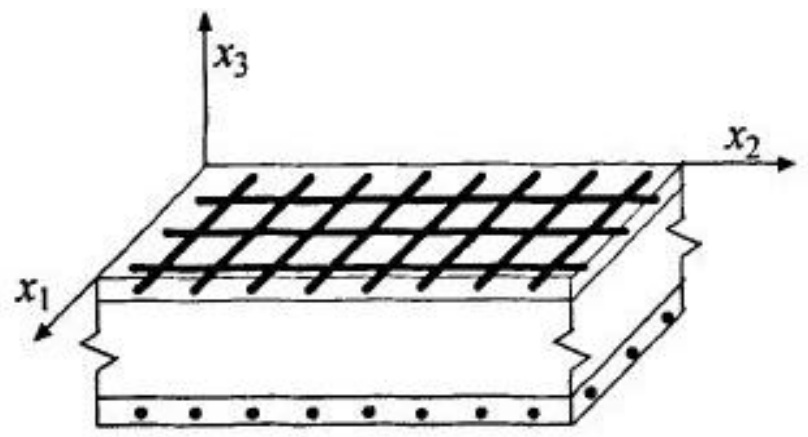

Fig. (8). The coordinate system of woven reinforced composite layer plate.

When the main direction $x_{l}$ subjects to tensile effect, the global and local coordinate systems coincide. According to axial conversion formula, the following forms can be obtained.

$$
\left\{\begin{array}{l}
\sigma_{11} \\
\sigma_{22} \\
\sigma_{12}
\end{array}\right\}=\left\{\begin{array}{l}
\sigma_{L} \\
0 \\
0
\end{array}\right\} \text { and }\left\{\begin{array}{l}
\varepsilon_{11} \\
\varepsilon_{22} \\
\varepsilon_{12}
\end{array}\right\}=\left\{\begin{array}{l}
\varepsilon_{L} \\
\varepsilon_{T} \\
0
\end{array}\right\}
$$

According to tensile test results, the elastic modulus and Poisson's ratio of the composite material can be expressed as: 


$$
\left\{\begin{array}{l}
E_{1}=E_{2}=\sigma_{L} / \varepsilon_{L}=3314.73 \mathrm{MPa} \\
v_{12}=v_{13}=\varepsilon_{T} / \varepsilon_{L}=0.25
\end{array}\right.
$$

The elastic constant in $\mathrm{z}$ direction (perpendicular to the layer) is approximately equal to the resin matrix. The elastic modulus and Poisson's ratio of this resin can be expressed as $E_{3}=907.42 \mathrm{MPa}, v_{23}=0.072$. Main direction strength is calculated using the following equation:

$$
\sigma=F / b d
$$

Main direction strength $\sigma_{11}$ is about $670 \mathrm{MPa}$. Interlaminar shear modulus parameters are not independent and Eq. (4) shows the relationship of three projects elastic constants, $E, G$ and $V$.

$$
G=\frac{E}{2(1+v)}
$$

Substituing Eq. (2) into Eq. (4), thus, interlaminar shear modulus can be expressed as $G_{12}=G_{13}=1325.892 \mathrm{MPa}, G_{23}$ $=423.237 \mathrm{MPa}$.

According to the mechanical properties of the elastic plate, stress-strain relationship during loading conforms to the generalized Hooke's law and can be expressed as

$$
\left[\begin{array}{l}
\sigma_{1} \\
\sigma_{2} \\
\sigma_{3} \\
\tau_{23} \\
\tau_{31} \\
\tau_{12}
\end{array}\right]=\left[\begin{array}{llllll}
C_{11} & C_{12} & C_{13} & C_{14} & C_{15} & C_{16} \\
C_{21} & C_{22} & C_{23} & C_{24} & C_{25} & C_{26} \\
C_{31} & C_{32} & C_{33} & C_{34} & C_{35} & C_{36} \\
C_{41} & C_{42} & C_{43} & C_{44} & C_{45} & C_{46} \\
C_{51} & C_{52} & C_{53} & C_{54} & C_{55} & C_{56} \\
C_{61} & C_{62} & C_{63} & C_{64} & C_{65} & C_{66}
\end{array}\right]\left[\begin{array}{l}
\varepsilon_{1} \\
\varepsilon_{2} \\
\varepsilon_{3} \\
\gamma_{23} \\
\gamma_{31} \\
\gamma_{12}
\end{array}\right]
$$

In the theory of elasticity, the majority of anisotropic materials have symmetrical internal structure. Suppose there are two orthogonal symmetric elastic material, taking $X_{1}-X_{3}$ plane as symmetry plane, flexibility matrix can be expressed as

$$
\left[\begin{array}{cccccc}
\frac{1}{E_{1}} & -\frac{v_{21}}{E_{2}} & -\frac{v_{31}}{E_{3}} & 0 & 0 & 0 \\
-\frac{v_{12}}{E_{1}} & \frac{1}{E_{2}} & -\frac{v_{32}}{E_{3}} & 0 & 0 & 0 \\
-\frac{v_{13}}{E_{1}} & -\frac{v_{23}}{E_{2}} & \frac{1}{E_{3}} & 0 & 0 & 0 \\
& & & \frac{1}{G_{23}} & 0 & 0 \\
& S Y M & & & \frac{1}{G_{13}} & 0 \\
& & & & & \frac{1}{G_{12}}
\end{array}\right]
$$

Where $E_{1}, E_{2}, E_{3}$ are Young's modulus, and $G_{12}, G_{13}, G_{23}$ are shear modulus.

According to the flexibility coefficient and the relationships between the elastic constants of engineering, the flexibility matrix is solved.

Eq. (7) is obtained by substituting the experimental results of tensile test. 


$$
\left\{\begin{array}{l}
S_{11}=\frac{1}{E_{1}}=\frac{1}{3314.73}=3.02 \times 10^{-4} \\
S_{22}=\frac{1}{E_{2}}=\frac{1}{3314.73}=3.02 \times 10^{-4} \\
S_{33}=\frac{1}{E_{3}}=\frac{1}{907.42}=1.1 \times 10^{-3} \\
S_{12}=-\frac{v_{12}}{E_{1}}=-\frac{0.25}{3314.73}=-7.54 \times 10^{-5} \\
S_{13}=-\frac{v_{13}}{E_{1}}=-\frac{0.25}{3314.73}=-7.54 \times 10^{-5} \\
S_{44}=\frac{1}{G_{23}}=\frac{1}{423}=2.36 \times 10^{-3} \\
S_{23}=-\frac{v_{23}}{E_{2}}=-\frac{0.072}{3314.73}=-2.017 \times 10^{-5} \\
S_{55}=\frac{1}{G_{13}}=\frac{1}{1325}=7.54 \times 10^{-4} \\
S_{66}=\frac{1}{G_{12}}=\frac{1}{1325}=7.54 \times 10^{-4}
\end{array}\right.
$$

Stiffness coefficient $C_{i j}$ Eq. (8) is obtained by the flexibility matrix inversion.

$$
\left\{\begin{array}{l}
C_{11}=\frac{1-v_{23} v_{32}}{E_{2} E_{3} \Delta}=\frac{1-0.072 \times 0.0197}{3314.73 \times 907.42 \times 8.63 \times 10^{-11}}=3826.2 \\
C_{22}=\frac{1-v_{31} v_{13}}{E_{1} E_{3} \Delta}=\frac{1-0.0684 \times 0.25}{3314.73 \times 907.72 \times 8.63 \times 10^{-11}}=3605.8 \\
C_{33}=\frac{1-v_{12} v_{21}}{E_{1} E_{2} \Delta}=\frac{1-0.25 \times 0.25}{3314.73 \times 3314.73 \times 8.63 \times 10^{-11}}=3605.8 \\
C_{12}=\frac{v_{12}+v_{31} v_{23}}{E_{2} E_{3} \Delta}=\frac{v_{12}+v_{32} v_{13}}{E_{1} E_{3} \Delta}=\frac{0.25+0.0197 \times 0.25}{3314.73 \times 907.42 \times 8.63 \times 10^{-11}}=17.3 \\
C_{13}=\frac{v_{21}+v_{21} v_{32}}{E_{2} E_{3} \Delta}=\frac{v_{13}+v_{12} v_{23}}{E_{1} E_{2} \Delta}=\frac{0.25+0.25 \times 0.072}{3314.73 \times 3314.73 \times 8.63 \times 10^{-11}}=282 \\
C_{23}=\frac{v_{32}+v_{12} v_{31}}{E_{1} E_{3} \Delta}=\frac{v_{23}+v_{21} v_{13}}{E_{1} E_{2} \Delta}=\frac{0.072+0.25 \times 0.25}{3314.73 \times 907.42 \times 8.63 \times 10^{-11}}=517.3
\end{array}\right.
$$

in which,

$$
\begin{gathered}
\Delta=\frac{1}{E_{1} E_{2} E_{3}}\left|\begin{array}{ccc}
1 & -v_{21} & -v_{31} \\
-v_{12} & 1 & -v_{32} \\
-v_{13} & -v_{23} & 1
\end{array}\right|=8.63 \times 10^{-11} \\
v_{21}=v_{12} \frac{E_{2}}{E_{1}}=0.25 \\
v_{31}=v_{13} \frac{E_{3}}{E_{1}}=0.0684 \\
v_{32}=v_{23} \frac{E_{3}}{E_{2}}=0.0197
\end{gathered}
$$


Substituting the above results into Eq.6, it can obtain the elastic constitutive model of glass fiber reinforced composite.

$$
\left[\begin{array}{c}
\sigma_{1} \\
\sigma_{2} \\
\sigma_{3} \\
\tau_{23} \\
\tau_{31} \\
\tau_{12}
\end{array}\right]=\left[\begin{array}{cccccc}
3826.2 & 17.3 & 282 & 0 & 0 & 0 \\
& 3605.8 & 517.3 & 0 & 0 & 0 \\
& & 3605.8 & 0 & 0 & 0 \\
& & & 423 & 0 & 0 \\
& S Y M & & & 1325 & 0 \\
& & & & & 1325
\end{array}\right]\left[\begin{array}{l}
\varepsilon_{1} \\
\varepsilon_{2} \\
\varepsilon_{3} \\
\gamma_{23} \\
\gamma_{31} \\
\gamma_{12}
\end{array}\right]
$$

\subsection{Failure Criteria}

The failure criteria based on failure mechanisms was established by Hashin who in 1973 proposed two failure criteria considering the quadratic interaction between tractions acting on failure plane based on his own experimental observations of tensile specimen failures, one related to fiber failure and another one related to matrix failure. After that, in 1980, he furthermore deduced the fiber and matrix failure criteria distinguished by tension and compression statuses. In the failure modes of lamina, the method of Hashin is best suited for determining failure criteria. The coefficients in the quadratic polynomials are related to a series of strength parameters $X \mathrm{t}, X \mathrm{c}, Y \mathrm{t}, S_{12}$, and $S_{23}$, which can be obtained from simple uniaxial compressions and tensions. In a practical application, the transverse and axial shear strength parameters are proposed to be equal. As the plane stress assumptions have been conducted, the following four failure criteria are constructed as follows:

$$
\begin{array}{ll}
\text { Tensile fiber damage mode } & \left(\frac{\sigma_{1}}{X_{t}}\right)^{2}+\left(\frac{\tau_{12}}{S_{12}}\right)^{2}=1 \\
\text { Compressive fiber damage mode } & \left(\frac{\sigma_{1}}{X_{c}}\right)^{2}=1 \\
\text { Tensile matrix damage mode } & \left(\frac{\sigma_{2}}{Y_{t}}\right)^{2}+\left(\frac{\tau_{12}}{S_{12}}\right)^{2}=1 \\
\text { Compressive matrix damage mode } & \left(\frac{\sigma_{2}}{Y_{t}}\right)\left[\left(\frac{Y_{c}}{2 S_{23}}\right)-1\right]+\left(\frac{\sigma_{2}}{2 S_{23}}\right)^{2}+\left(\frac{\tau_{12}}{S_{12}}\right)=1
\end{array}
$$

Material parameters of the glass-epoxy laminae are expressed as Table 1. The damaging effect resulting from the shear stresses and normal stresses in matrix and fibers frequently occurs on matrix or fiber-matrix interface, which often leads to debonding. In common the bonding strength of fiber-matrix interface is the lower in comparison with the strength of single constituents. The cracks in matrix soon transmit into fiber-matrix interface and propagate along fibers without crossing into fiber material. In common, yield and longitudinal shear failure are the main two causes inducing longitudinal compressive failure of composite. In further the compressive strength can be characterized by two models, and the first one is tension or compression damage model, meanwhile the second one is shear damage. They are written as

Table 1. Material parameters of composites.

\begin{tabular}{|c|c|c|c|c|c|c|c|c|c|c|c|c|}
\hline $\boldsymbol{E}_{\mathbf{1}}$ & $\boldsymbol{E}_{\mathbf{2}}$ & $\boldsymbol{E}_{\mathbf{3}}$ & $\boldsymbol{v}_{\mathbf{1 2}}$ & $\boldsymbol{v}_{\mathbf{1 3}}$ & $\boldsymbol{v}_{\mathbf{2 3}}$ & $\boldsymbol{G}_{\mathbf{1 2}}$ & $\boldsymbol{G}_{13}$ & $\boldsymbol{G}_{\mathbf{2 3}}$ & $\boldsymbol{X}_{\mathbf{t}}$ & $\boldsymbol{\sigma}_{\mathrm{f}}$ & $\boldsymbol{a}_{\mathbf{k}}$ & $a_{k}^{\prime}$ \\
\hline 3314.73 & 3314.73 & 907.42 & 0.25 & 0.25 & 0.072 & 1325 & 1325 & 423 & 670 & 101.4 & 15.7 & 23.4 \\
\hline
\end{tabular}




$$
\left\{\begin{array}{l}
X_{c}=2 V_{f} \sqrt{\frac{0.63 E_{f} E_{m} V_{f}}{3\left(1-V_{f}\right)}} \\
X_{c}=\frac{0.63 G_{m}}{1-V_{f}}
\end{array}\right.
$$

The longitudinal compressive strength of composite selects the smaller one, then $X_{c}=666.59 \mathrm{MPa}$ can be obtained. Substituting Eq.7, Table 1 and $X_{c}$ into the Eq. 10, the Failure criteria finally becomes

$$
\left\{\begin{array}{l}
\left(\frac{\sigma_{1}}{670}\right)^{2}+\left(\frac{\tau_{12}}{1325}\right)^{2}=1 \\
\left(\frac{\sigma_{1}}{666.7}\right)^{2}=1 \\
\left(\frac{\sigma_{2}}{670}\right)^{2}+\left(\frac{\tau_{12}}{1325}\right)^{2}=1 \\
\left(\frac{\sigma_{2}}{670}\right)\left[\left(\frac{Y_{C}}{423}\right)-1\right]+\left(\frac{\sigma_{2}}{423}\right)^{2}+\left(\frac{\tau_{12}}{1325}\right)=1
\end{array}\right.
$$

\subsection{Simulation of Impact Tests on Composite Plate}

The established failure criteria are usually inserted into finite element method to predict and describe failure behaviors in composite materials. The developed constitutive equation is incorporated into a finite element code. It can simulate the actual production and the results can provide a theoretical reference. The simulations of trial impact with damage/delamination model in ABAQUS/Explicit solver on ideal GFRP laminates are modeled. The plates consist of 6 plies of E-glass fabric/epoxy, and their nominal dimensions are $80 \times 80 \times 4 \mathrm{~mm}$. In the trial impact a steel sphere impactor with a diameter of $50 \mathrm{~mm}$ and an added density of $7.8 \mathrm{~g} / \mathrm{cm}^{3}$ shown in Fig. (9) is often adopted. The dimension data of the composite is imported, and then the surfaces are meshed. As the material thickness is small, shell element is suite. The parameters of impactor are shown in Table 2.

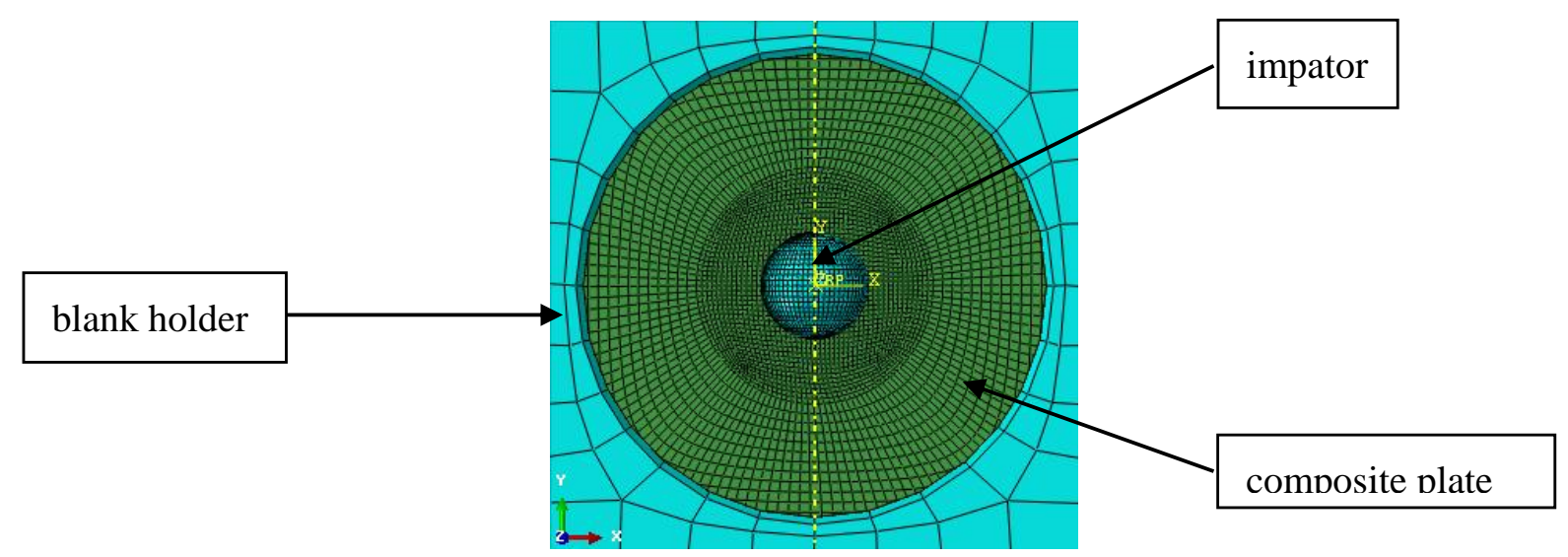

Fig. (9). The projectile and laminated composite plate model.

Table 2. Material parameters of projectile.

\begin{tabular}{|c|c|c|}
\hline $\boldsymbol{\rho}\left(\mathrm{kg} / \mathbf{m}^{3}\right)$ & $\boldsymbol{E}(\mathbf{M P a})$ & $\boldsymbol{v}$ \\
\hline 7800 & $2.0 \times 10^{5}$ & 0.33 \\
\hline
\end{tabular}

Orthotropic elastic constitutive model and Hashin failure criteria are used in 2D woven E-glass laminate and the parameters of them are shown in Tables $\mathbf{3}$ and $\mathbf{4}$ respectively. The composite plate is impacted at its center with a rigid impactor, meanwhile it is supported over the frame. The simulation results corresponding to an impact velocity of 55 $\mathrm{m} / \mathrm{s}$ are shown in Fig. (10). These figures show that with the increase of deformation time deformation gradually 
increases until rupture of composite panels. From the deformation process under the impact effect in Fig. (10), it can be seen that the deformation of plate is small in the initial stage. With the increasing of the impact load, the deformation of plate gradually increases. When the impact load reaches a critical material damage value $(732 \mathrm{~N})$, the plate begins to break. After about $24 \mu \mathrm{s}$, material deformation reaches the maximum and reallocation occurs subsequently.

Table 3. Material properties for orthotropic model.

\begin{tabular}{|c|c|c|c|c|c|c|c|c|c|}
\hline $\boldsymbol{\rho}\left(\mathbf{k g} / \mathbf{m}^{\mathbf{3}}\right)$ & $\boldsymbol{E}_{\mathbf{1}}$ & $\boldsymbol{E}_{\mathbf{2}}$ & $\boldsymbol{E}_{\mathbf{3}}$ & $\boldsymbol{v}_{\mathbf{1 2}}$ & $\boldsymbol{v}_{\mathbf{1 3}}$ & $\boldsymbol{v}_{\mathbf{2 3}}$ & $\boldsymbol{G}_{\mathbf{1 2}}$ & $\boldsymbol{G}_{\mathbf{1 3}}$ & $\boldsymbol{G}_{\mathbf{2 3}}$ \\
\hline 1100 & 3314.73 & 3314.73 & 907.42 & 0.25 & 0.25 & 0.072 & 1325 & 1325 & 423 \\
\hline
\end{tabular}

Table 4. Material properties for failure criterion.

\begin{tabular}{|c|c|c|c|c|c|c|c|c|c|}
\hline $\boldsymbol{X}_{\boldsymbol{t}}$ & $\boldsymbol{X}_{\boldsymbol{c}}$ & $\boldsymbol{Y}_{\boldsymbol{t}}$ & $\boldsymbol{Y}_{\boldsymbol{c}}$ & $\boldsymbol{S}_{\boldsymbol{1}}$ & $\boldsymbol{S}_{\boldsymbol{c}}$ & $\boldsymbol{G}_{\boldsymbol{1}_{+}}$ & $\boldsymbol{G}_{\boldsymbol{1}}$ & $\boldsymbol{G}_{2+}$ & $\boldsymbol{G}_{2-}$ \\
\hline 67 & 60.3 & 67 & 60.3 & 84 & 84 & $5 \mathrm{E}-6$ & $5 \mathrm{E}-6$ & $6 \mathrm{E}-6$ & $6 \mathrm{E}-6$ \\
\hline
\end{tabular}

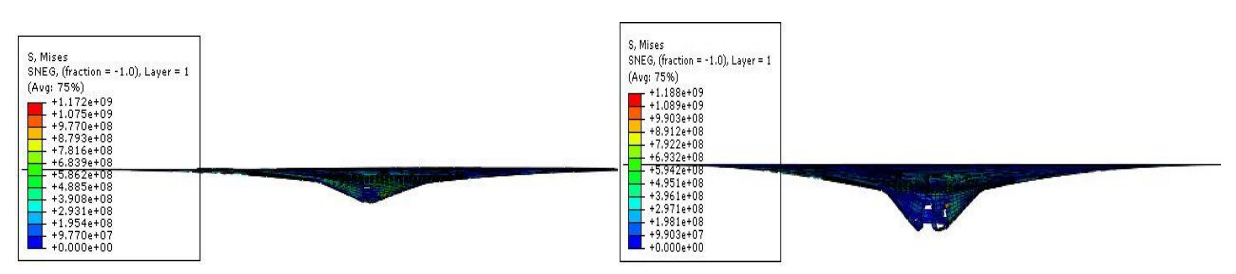

(a) $6 \mu \mathrm{s}$

(b) $12 \mu \mathrm{s}$

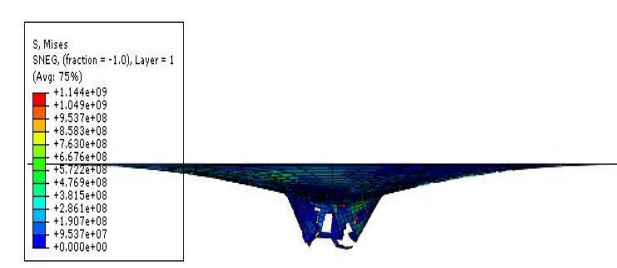

(c) $18 \mu \mathrm{s}$

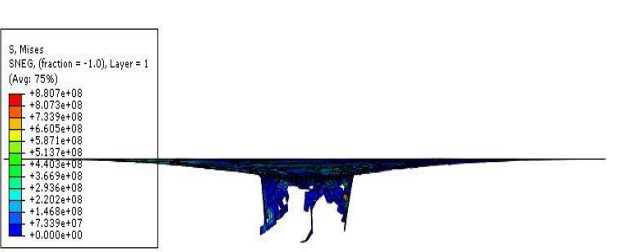

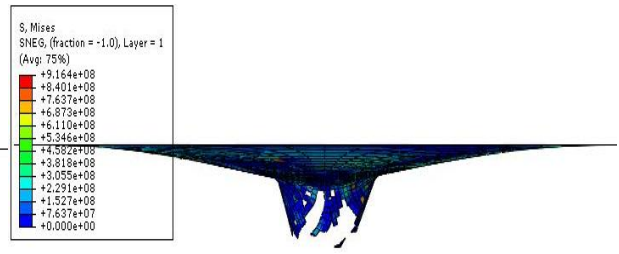

(d) $24 \mu \mathrm{s}$

(e) $30 \mu \mathrm{s}$

Fig. (10). Deformation process under the impact effect.

Fig. (11) shows the typical deformation plots and stress contours during this impact event at an impact velocity of $55 \mathrm{~m} / \mathrm{s}$. In the initial stage of the impact, the stress (as shown in Fig. (11a)) is "cross-petal-shaped" distribution, which is because that transverse and longitudinal of composite laminates are the main fiber direction and suffer the most of the tensile stress. As shown in Fig. (11a) d, material damage area increases with the prolonging of time. From Fig. (11b), it can be seen that stress gradually spreads to the surrounding from 619.6 MPa to $0 \mathrm{MPa}$. Fig. (11d) shows that at the maximal deformation during the impact process stress gradually increases outwards and it can be seen that the stress value of composite with $0 \mathrm{MPa}$ becomes greater to $254.9 \mathrm{MPa}, 509.8 \mathrm{MPa}$ respectively after $24 \mu$ s corresponding to three points of 1,2 , and 3 . Throughout the entire process, the material damage decrease radially from the center to the edges. As shown in Fig. (11), for a fixed time, material damage gradually increases from the edges to the center and reaches a constant value of 1 , which means that the rupture of the damage process. 


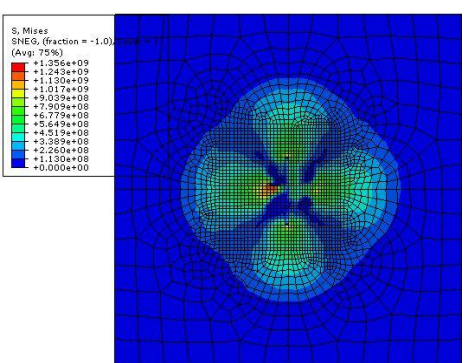

(a) $6 \mu \mathrm{s}$

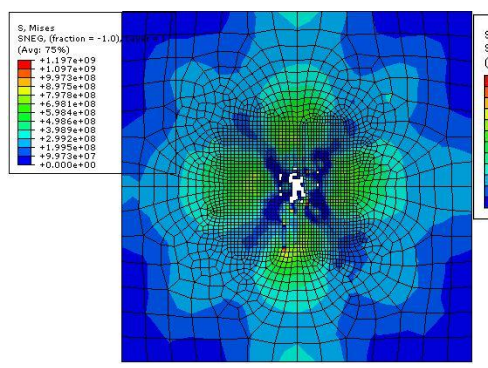

(c) $18 \mu \mathrm{s}$

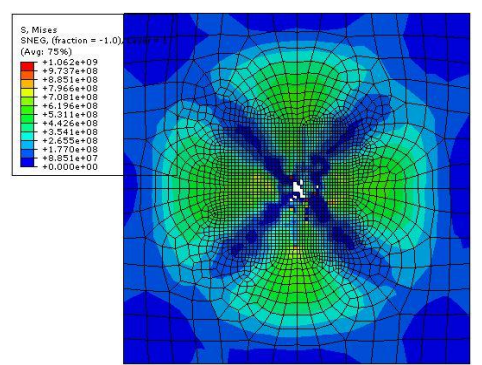

(b) $12 \mu \mathrm{s}$

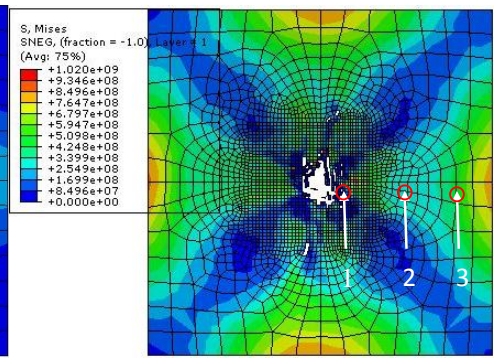

(d) $24 \mu \mathrm{s}$

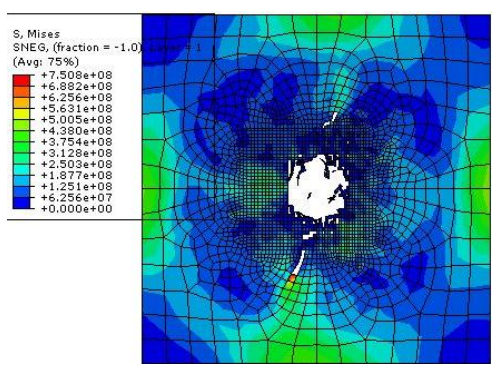

(e) $30 \mu \mathrm{s}$

Fig. (11). Stress distribution rule under the impact effect.

\section{CONCLUSION}

The dynamic tensile testing was performed at a constant velocity of $2 \mathrm{~mm} / \mathrm{min}$ until the sample breaks. Through analysis of the experiment results and simulation the process of projectile impacting GFRP composite laminates, the following conclusions were drawn.

1. The observation by optical microscope reveal that the fracture of the laminated composite reinforced with Eglass woven fabrics is smooth, which indicates the material has negligible ductility. The E-glass woven fabrics in the laminated composite have been pulled out from their matrix, and the E-glass fibers as strengthen part have become straight under large pullout energy.

2. A continuum damage model for predicting damage in GFRP laminates has been established, and it is suited for the applications in finite element method.

3. The simulation results have showed that the material deformation reached a maximum after about $24 \mu \mathrm{s}$, then rebound occurred with the increase of the time. The stress of reinforcements traverse section gradually increased outward from $0 \mathrm{MPa}$ to $509.8 \mathrm{MPa}$. Throughout the entire process, the material damage decrease radially from the center to the edges. When the damage value of the center reaches 1 , surrounded damage value tends to 0 .

\section{CONFLICT OF INTEREST}

The authors confirm that this article content has no conflict of interest. 


\section{ACKNOWLEDGEMENTS}

This work was supported by the open funds of State Key Laboratory of Vehicle NVH and Safety Technology of China (NVHSKL-201101).

\section{REFERENCES}

[1] Ryou H, Chung K, Yu WR. Constitutive modeling of woven composites considering asymmetric/anisotropic, rate dependent, and nonlinear behavior. Compos Part A-Appl S 2007; 38: 2500-10.

[2] Johnson AF, Pickett AK, Rozycki P. Computational methods for predicting impact damage in composite structures. Compos Sci Technol $2001 ; 61: 2183-92$.

[http://dx.doi.org/10.1016/S0266-3538(01)00111-7]

[3] De Moura MF, Gonçalves JP. Modelling the interaction between matrix cracking and delamination in carbon-epoxy laminates under low velocity impact. Compos Sci Technol 2004; 64: 1021-7. [http://dx.doi.org/10.1016/j.compscitech.2003.08.008]

[4] Potluri P, Manan A. Mechanics of non-orthogonally interlaced textile composites. Compos Part A-Appl S 2007; 38: 1216-26.

[5] Lomov SV, Ivanov DS, Verpoest I, et al. Meso-FE modelling of textile composites: Road map, data flow and algorithms. Compos Sci Technol 2007; 67: 1870-91.

[http://dx.doi.org/10.1016/j.compscitech.2006.10.017]

[6] Roy AK. Comparison of in situ damage assessment in unbalanced fabric composite and model laminate of planar (one-directional) crimping. Compos Sci Technol 1998; 58: 1793-801. [http://dx.doi.org/10.1016/S0266-3538(98)00045-1]

[7] Nicoletto G, Riva E. Failure mechanisms in twill-weave laminates: FEM predictions vs. experiments. Compos Part A-Appl S 2004; 35: 787-95.

[8] Key CT, Schumacher SC, Hansen AC. Progressive failure modeling of woven fabric composite materials using multicontinuum theory. Compos Part B Eng 2007; 38: 247-57.

[http://dx.doi.org/10.1016/j.compositesb.2006.03.006]

[9] Karakuzu R, Gülem T, İçten BM. Failure analysis of woven laminated glass-vinylester composites with pin-loaded hole. Compos Struct 2006; 72: 27-32.

[http://dx.doi.org/10.1016/j.compstruct.2004.10.009]

[10] Iannucci L. Progressive failure modelling of woven carbon composite under impact. Int J Impact Eng 2006; 32 : 1013-43. [http://dx.doi.org/10.1016/j.ijimpeng.2004.08.006]

[11] Gao F, Boniface L, Ogin SL, Smith PA, Greaves RP. Damage accumulation in woven fabric CFRP laminates under tensile loading: Part 1. Observations of damage accumulation. Compos Sci Technol 1999; 59: 123-36. [http://dx.doi.org/10.1016/S0266-3538(97)00231-5]

[12] Hochard C, Aubourg PA, Charles JP. Modelling of the mechanical behaviour of woven fabric CFRP laminates up to failure. Compos Sci Technol 2001; 61: 221-30. [http://dx.doi.org/10.1016/S0266-3538(00)00199-8]

[13] Lua J. Thermal-mechanical cell model for unbalanced plain weave woven fabric composites. Compos Part A-Appl S 2007; 38: 1019-37.

[14] McIlhagger R, Quinn JP, McIlhagger AT, Wilson S, Simpson D, Wenger W. The influence of binder tow density on the mechanical properties of spatially reinforced composites. Part 2-Mechanical properties. Compos Part A-Appl S 2008; 39: 334-41.

[15] Peng XQ, Cao J. A continuum mechanics-based non-orthogonal constitutive model for woven composite fabrics. Compos Part A-Appl S 2005; 36: 859-74.

[16] Yu WR, Pourboghrat F, Chung K, Zampaloni M, Kang TJ. Nonorthogonal constitutive equation for woven fabric reinforced thermoplastic composites. Compos Part A-Appl S 2002; 33: 1095-105.

[17] Davies GA, Zhang X. Impact damage prediction in carbon composite structures. Int J Impact Eng 1995; 16: 149-70. [http://dx.doi.org/10.1016/0734-743X(94)00039-Y]

[18] Hou JP, Petrinic N, Ruiz C, Hallett SR. Prediction of impact damage in composite plates. Compos Sci Technol 2000; 60: $273-81$. [http://dx.doi.org/10.1016/S0266-3538(99)00126-8]

[19] Zheng S, Sun CT. A double-plate finite-element model for the impact-induced delamination problem. Compos Sci Technol 1995; 53: 111-8. [http://dx.doi.org/10.1016/0266-3538(94)00079-4]

(C) 2017 Yang and Tong.

This is an open access article distributed under the terms of the Creative Commons Attribution 4.0 International Public License (CC-BY 4.0), a copy of which is available at: (https://creativecommons.org/licenses/by/4.0/legalcode). This license permits unrestricted use, distribution, and reproduction in any medium, provided the original author and source are credited. 